\title{
Instrumental Activities of Daily Living Impairment Is Associated with Increased Amyloid Burden
}

\author{
Gad A. Marshall ${ }^{a, b} \quad$ Lauren E. Olson ${ }^{a, b}$ Meghan T. Frey ${ }^{a} \quad$ Jacqueline Maye \\ J. Alex Becker ${ }^{c}$ Dorene M. Rentz ${ }^{a, b}$ Reisa A. Sperling ${ }^{a, b}$ \\ Keith A. Johnson ${ }^{a, c}$ Alzheimer's Disease Neuroimaging Initiative \\ ${ }^{a}$ Center for Alzheimer Research and Treatment, Department of Neurology, Brigham and Women's Hospital, \\ and Departments of ${ }^{b}$ Neurology and ' Radiology, Massachusetts General Hospital, Harvard Medical School, \\ Boston, Mass., USA
}

\section{Key Words}

Alzheimer's disease $\cdot$ Amyloid $\cdot$ Instrumental activities of daily living $\cdot$ Mild cognitive impairment $\cdot$ Pittsburgh compound $\mathrm{B} \cdot$ Positron emission tomography

\begin{abstract}
Background/Aims: Instrumental activities of daily living (IADL) impairment in Alzheimer's disease has been associated with global amyloid deposition in postmortem studies. We sought to determine whether IADL impairment is associated with increased cortical Pittsburgh Compound B (PiB) retention. Methods: Fifty-five subjects (19 normal older controls, NC, and 36 with mild cognitive impairment, $\mathrm{MCl}$ ) underwent clinical assessments and dynamic PiB positron emission tomography imaging. Results: A linear multiple regression model showed that greater IADL impairment was associated with greater global $\mathrm{PiB}$ retention in all subjects $\left(R^{2}=0.40\right.$; unstandardized partial regression coefficient, $\beta=$ 5.8; $p=0.0002)$ and in $\mathrm{MCl}$ subjects only $\left(\mathrm{R}^{2}=0.28 ; \beta=6.1\right.$; $\mathrm{p}=0.003)$, but not in NC subjects only. Conclusion: These results suggest that daily functional impairment is related to greater amyloid burden in $\mathrm{MCl}$.
\end{abstract}

Copyright $\odot 2011$ S. Karger AG, Basel

\section{Introduction}

Instrumental activities of daily living (IADL) consist of many everyday activities, such as handling the finances, using public transportation or driving, shopping for clothes and food, preparing meals, cleaning, and doing the laundry. Impairments in IADL typically develop as patients transition from amnestic mild cognitive impairment (MCI) to dementia. IADL impairment greatly increases caregiver burden and is a hallmark of Alzheimer's disease (AD). IADL impairment in $\mathrm{AD}$ has been associated with inferior parietal, superior occipital, and inferior temporal hypometabolism in vivo [1], and with global amyloid deposition in postmortem studies [2].

Part of the data used in this article was obtained from the ADNI database (www.loni.ucla.edu/ADNI). The authors are site investigators for ADNI at Brigham and Women's Hospital and Massachusetts General Hospital. The other site investigators within the ADNI contributed to the design and implementation of ADNI and/or provided data, but did not participate in analysis or writing of this report. Complete listing of ADNI investigators available at www.loni.ucla.edu/ADNI/ Collaboration/ADNI_Authorship_list.pdf.

\section{KARGER}

() 2011 S. Karger AG, Basel

Fax +41613061234 E-Mail karger@karger.ch www.karger.com www.karger.com/dem
Gad A. Marshall, MD

Center for Alzheimer Research and Treatment

Brigham and Women's Hospital, 221 Longwood Avenue, BL-104H

Boston, MA 02115 (USA)

Tel. +1 617732 8085, E-Mail gamarshall@ partners.org 
Fig. 1. PiB distribution volume ratio (DVR) images from two transaxial levels representing NC, MCI, and AD subjects. These images exemplify the observation that $\mathrm{PiB}$ binding, similar to that seen in AD subjects, was seen in subsets of both NC and MCI subjects. MMSE = Mini-Mental State Examination; PiB-neg $=\mathrm{PiB}$ negative; $\mathrm{PiB}-\mathrm{pos}=\mathrm{PiB}$ positive; $\mathrm{y} / \mathrm{o}=$ years old.

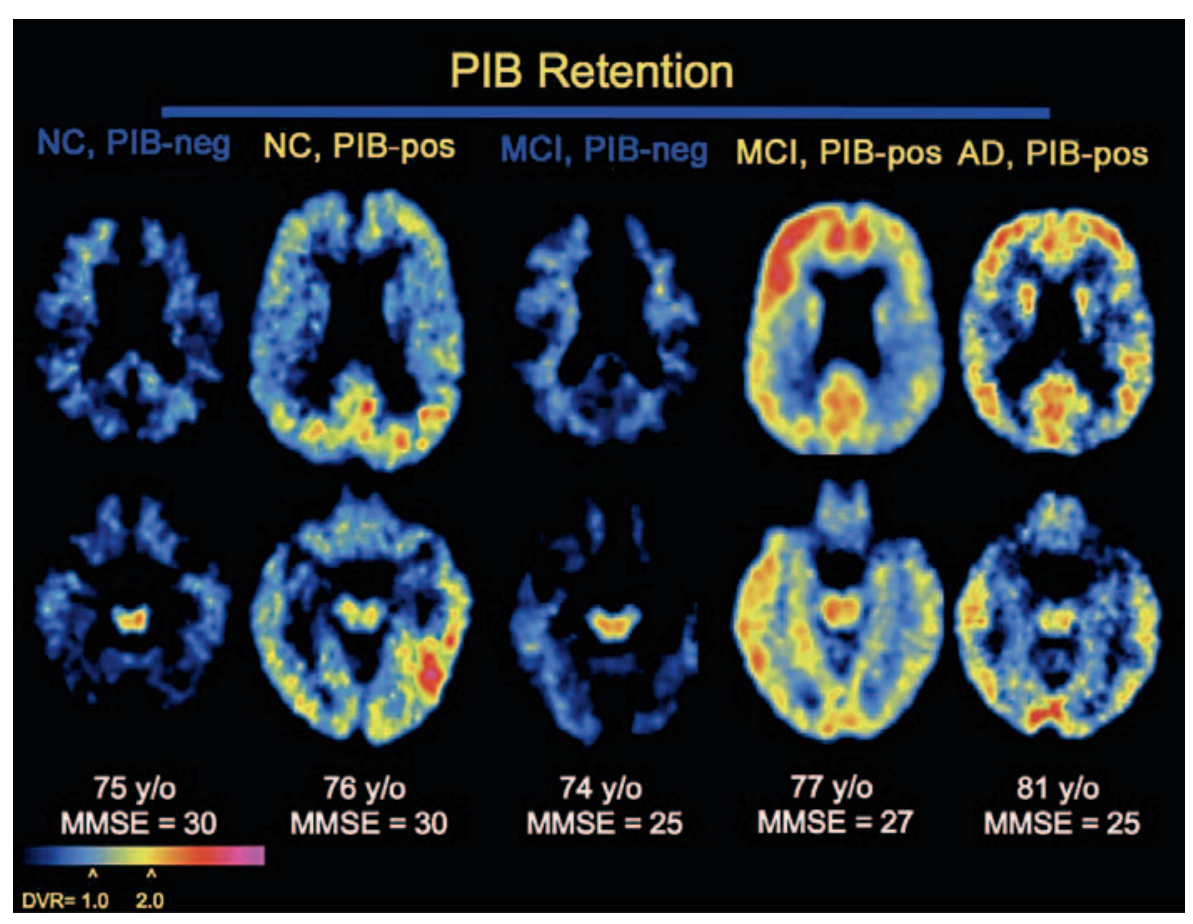

With the advent of Pittsburgh Compound $\mathrm{B}(\mathrm{PiB})$ positron emission tomography (PET) imaging [3], it is now possible to visualize amyloid deposition in vivo much earlier in the disease process, well before dementia becomes evident. Multiple studies of MCI subjects have shown a bimodal distribution of increased $\mathrm{PiB}$ binding, with one MCI group demonstrating $\mathrm{PiB}$ retention at the level of $\mathrm{AD}$ patients and the other demonstrating only non-specific binding similar to PiB-negative normal controls (NC) [4-10] (fig. 1). Similarly, studies of postmortem evaluations of MCI have shown heterogeneity in pathology among MCI subjects with nearly half of the subjects having minimal amyloid pathology $[11,12]$. Given the significant pathologic variability across MCI subjects, additional information is necessary in order to predict which subset of MCI subjects harbors AD pathology and will decline to dementia. Additional clinical manifestations, such as IADL impairment, may be important markers of impending decline.

Several studies have shown an association between increased $\mathrm{PiB}$ retention and reduced cognitive performance, especially memory impairment, across a range of subjects with normal cognition, MCI, and AD [13-15]. Another study found that the Clinical Dementia Rating (CDR) scale [16], which is highly dependent on activities of daily living, was correlated with $\mathrm{PiB}$ retention across subjects with different dementias [7]. To our knowledge there have been no studies that have assessed the relationship between IADL and in vivo amyloid deposition in MCI. We therefore set out to investigate whether subtle IADL impairment may be present in MCI subjects with high amyloid burden.

We sought to determine whether IADL impairment is associated with increased cortical $\mathrm{PiB}$ retention in nondemented elderly subjects, including MCI and NC subjects, while accounting for age, cognitive reserve, global cognitive impairment, and memory performance. We further focused on the MCI subjects since we did not expect to find significant IADL impairment in the NC subjects. Both IADL impairment and PiB retention have each been associated with global cognitive impairment and memory impairment. Therefore, we used a linear multiple regression model in which the potential contributions of cognitive impairment and amyloid pathology toward IADL impairment could be independently assessed. We hypothesized that greater IADL impairment would be associated with greater global cortical $\mathrm{PiB}$ retention.

Default network dysfunction has been associated with IADL impairment [1] and with PiB retention $[8,17]$. Therefore, we sought to determine whether IADL impairment is associated with greater $\mathrm{PiB}$ retention in the default network. Global cortical PiB retention is highly correlated with regional $\mathrm{PiB}$ retention in other cortices with the exception of the medial temporal lobe where $\mathrm{PiB}$ retention is 
lower [18]. As such, regionally specific associations with clinical or cognitive assessments are difficult to detect [1820]. Nonetheless, we attempted to identify, in an exploratory analysis, whether a specific regional pattern of cortical $\mathrm{PiB}$ retention is associated with IADL impairment.

\section{Subjects and Methods}

\section{Subjects}

Part of the data used in the preparation of this article were obtained from the Alzheimer's Disease Neuroimaging Initiative (ADNI) database (www.loni.ucla.edu/ADNI) [21]. ADNI is a multicenter natural history trial consisting of NC, amnestic MCI, and mild AD subjects followed with longitudinal periodic imaging of multiple modalities, blood and cerebrospinal fluid, and clinical and neuropsychological assessments. The primary goals of ADNI include using these various assessments to measure the progression of MCI and mild $\mathrm{AD}$, determining the sensitivity and specificity of biomarkers in serving as surrogate outcome measures in treatment trials, and reducing the time and cost of clinical trials. ADNI is the result of efforts of many co-investigators from a broad range of academic institutions and private corporations, and subjects have been recruited from over 50 sites across the USA and Canada [21].

The rest of the data used in the preparation of this article were obtained from an investigator-initiated functional MRI ADNI ancillary study (R01 AG027435S) at Brigham and Women's Hospital and Massachusetts General Hospital.

Fifty-five subjects (19 NC and $36 \mathrm{MCI}$ ) participating in ADNI (22 of the $55 ; 4 \mathrm{NC}$ and $18 \mathrm{MCI}$ ) or an investigator-initiated ADNI ancillary (33 of the 55; $15 \mathrm{NC}$ and $18 \mathrm{MCI}$ ) who underwent dynamic PiB PET imaging were included in the current analysis. Subjects were aged 58-86 years (inclusive), were medically stable at screening, and had study partners able to provide collateral information. Subjects did not have significant neurological conditions, recent alcohol or substance abuse, or active psychiatric diagnoses. Subjects had a Geriatric Depression Scale score (short form [22]) $\leq 5$ or (long form [23]) $\leq 10$, and a modified Hachinski Ischemic Score $\leq 4$ [24].

NC subjects had a CDR global and sum of boxes score of 0 , Mini-Mental State Examination (MMSE) [25] score of 28-30 (inclusive), and did not have significant impairment in individual cognitive domains. MCI subjects met the criteria for single- or multiple-domain amnestic MCI [26]: memory complaint by subject or study partner; objective memory impairment on the logical memory IIa of the Weschler Memory Scale-Revised [27]; essentially preserved IADL (as assessed by the CDR); and not demented. MCI subjects had a global CDR score of 0.5 and memory box score $\geq 0.5$ and MMSE score 24-30 (inclusive).

The ADNI study and the investigator-initiated ADNI ancillary study were approved by the partners' (local) Institutional Review Board, as well as that of each site participating in ADNI. Prior to performance of any of the study procedures, informed consent was obtained from all subjects and study partners.

Clinical Assessments

IADL were assessed using the informant-based Functional Activities Questionnaire (FAQ) [28]. Higher scores on the FAQ indicate greater IADL impairment (range 0-14 in this analysis; full range 0-30). Most studies do not use a cutoff score for FAQ, but one study indicated that scores $\geq 6$ were consistent with functional impairment [29].

The following scales were also used in this analysis: the MMSE assesses global cognitive function (range 24-30 in this analysis; full range 0-30; lower scores on the MMSE indicate greater cognitive impairment); the Rey Auditory Verbal Learning Test (RAVLT) [30] assesses memory performance (the 30-min delayed recall score was used in this analysis; range $0-15$; lower scores on the RAVLT indicate greater memory impairment); the American National Adult Reading Test intelligence quotient (AMNART IQ) [31] provides an estimate of premorbid verbal intelligence (an error score was converted into an IQ score; IQ score range 84-131 in this analysis; full range 74-132; higher AMNART IQ scores indicate a higher level of intelligence), which serves as a proxy of cognitive reserve.

\section{PiB PET Imaging}

$\mathrm{PiB}$ was synthesized as described by Mathis, Klunk, and colleagues $[3,32]$. Dynamic PiB PET image acquisition was performed as previously described [19, 33]. Data for the investigatorinitiated ADNI ancillary were acquired using a Siemens/CTI (Knoxville, Tenn., USA) ECAT HR+ scanner (3D mode; 63 image planes; $15.2-\mathrm{cm}$ axial field of view; $5.6-\mathrm{mm}$ transaxial resolution, and 2.4-mm slice interval; 69 frames: $12 \times 15 \mathrm{~s}, 57 \times 60 \mathrm{~s}$ ). After a transmission scan, a bolus of $10-15 \mathrm{mCi}$ of ${ }^{11} \mathrm{C} \mathrm{PiB}$ was injected, followed immediately by a 60 -min dynamic acquisition (ADNI $\mathrm{PiB} P E T$ data used in this analysis had a 70-min dynamic acquisition). PiB PET data were reconstructed with ordered set expectation-maximization, corrected for attenuation. Each frame was evaluated to verify adequate count statistics and absence of head motion. Cortical PiB retention was evaluated using the distribution volume ratio (DVR), based on the Logan plots of time-activity curves (cerebellar reference) [34].

Regions of interest (ROI) were obtained using automated anatomical labeling [35]. In the primary analyses, a global $\mathrm{PiB}$ retention value consisting of an aggregate of cortical regions was used $[19,33,36]$. In the exploratory analyses, 6 ROI were used including mean of right and left occipital, precuneus, lateral parietal (supramarginal), medial temporal (parahippocampus), dorsolateral prefrontal (superior and middle frontal), and inferior orbitofrontal $\mathrm{PiB}$ retention.

\section{Data Analysis}

The majority of subjects had an FAQ score of 0 ( 30 of the 55), which is expected with a population of NC and MCI subjects. As such, the distribution of FAQ scores was skewed to the right. Therefore, when assessing the relationship of potential predictors with FAQ, Spearman's rank correlation $\left(\mathrm{r}_{\mathrm{s}}\right)$ was employed.

For our primary analysis in all subjects, a linear multiple regression model was employed with FAQ as the dependent variable and global PiB retention, age, AMNART IQ, MMSE, and RAVLT delayed recall as predictors. MMSE and RAVLT delayed recall negatively correlated significantly with FAQ in all subjects (RAVLT: $\mathrm{r}_{\mathrm{s}}=-0.34, \mathrm{p}=0.011$; MMSE: $\mathrm{r}_{\mathrm{s}}=-0.34, \mathrm{p}=0.011$ ) and therefore were included as predictors in order to more clearly demonstrate the independent effect of $\mathrm{PiB}$ retention on FAQ. Sex was not included as a predictor because there was no significant association between sex and FAQ. Although there was no 
Table 1. Demographics of subjects

\begin{tabular}{lccc}
\hline & All subjects & MCI & NC \\
\hline Subjects, $\mathrm{n}$ & 55 & 36 & 19 \\
Age, years & $74.6 \pm 7.2(58-86)$ & $73.4 \pm 7.7(58-86)$ & $76.7 \pm 6.0(64-86)$ \\
Sex, \% male & 61.8 & 80.6 & 26.3 \\
Education, years & $16.6 \pm 2.8(7-20)$ & $16.8 \pm 2.6(12-20)$ & $16.3 \pm 3.3(7-20)$ \\
AMNART IQ & $121.0 \pm 10.4(84-131)$ & $120.5 \pm 10.6(84-131)$ & $122.1 \pm 10.1(85-130)$ \\
MMSE & $28.5 \pm 1.4(24-30)^{*}$ & $28.1 \pm 1.5(24-30)$ & $29.2 \pm 0.9(28-30)$ \\
RAVLT delayed recall & $5.6 \pm 4.5(0-15)^{*}$ & $3.8 \pm 3.8(0-14)$ & $9.0 \pm 3.6(0-15)$ \\
CDR sum of boxes & $1.0 \pm 1.0(0-4)^{* *}$ & $1.5 \pm 0.9(1-4)^{* *}$ & 0 \\
FAQ & $2.4 \pm 3.7(0-14)$ & $3.5 \pm 4.1(0-14)$ & $0.2 \pm 0.7(0-3)$ \\
\hline
\end{tabular}

All values (except subjects and sex) represent means \pm SD with ranges in parentheses. CDR sum of boxes was 0 for all NC subjects as an inclusion criterion. Correlations with FAQ: ${ }^{*} \mathrm{p}<0.05,{ }^{* *} \mathrm{p}<0.001$.

significant correlation between age and FAQ, age was included in the model because of the previously described association between advancing age and greater PiB retention [19, 37]. Similarly, AMNART IQ, which did not significantly correlate with FAQ, was included in the model because of a previously described effect of cognitive reserve on $\mathrm{PiB}$ retention [15].

We then repeated the above analysis in MCI subjects only. A linear multiple regression model was employed with FAQ as the dependent variable and global $\mathrm{PiB}$ retention, age, and AMNART IQ as predictors. MMSE, RAVLT delayed recall, and sex were not included as predictors because they were not significantly associated with FAQ in MCI subjects only. However, since the regression model in all subjects included MMSE and RAVLT delayed recall as predictors, we reran the regression model in MCI subjects only with these predictors included, which did not alter the results. We repeated the above MCI subjects only analysis with the linear multiple regression model in NC subjects only.

Since FAQ had a skewed distribution in this sample, partial Spearman's rank correlations (coefficient $=\mathrm{pr}_{\mathrm{s}}$ ) were carried out in all subjects, MCI subjects only, and NC subjects only in order to confirm the results of the linear multiple regression models above. The same covariates included in the regression models were controlled for in the partial correlations.

For our exploratory analysis in all subjects, MCI subjects only, and NC subjects only, we employed Spearman's rank correlation to assess the relationship between FAQ and regional $\mathrm{PiB}$ retention in 6 ROI. Since all regions were highly inter-correlated, we did not follow-up with a linear multiple regression model as it appeared that the clinical association with $\mathrm{PiB}$ retention was a global association. All analyses were performed using SPSS.

\section{Results}

Table 1 provides demographic data for all subjects, MCI subjects only, and NC subjects only. MMSE and RAVLT delayed recall significantly negatively correlated with FAQ in all subjects (RAVLT: $\mathrm{r}_{\mathrm{s}}=-0.34, \mathrm{p}=0.011$;
MMSE: $\left.\mathrm{r}_{\mathrm{s}}=-0.34, \mathrm{p}=0.011\right)$, but not in MCI subjects only (RAVLT: $\mathrm{r}_{\mathrm{s}}=-0.14, \mathrm{p}=0.41 ;$ MMSE: $\mathrm{r}_{\mathrm{s}}=-0.23, \mathrm{p}=$ 0.17 ) or NC subjects only (RAVLT: $r_{s}=-0.04, p=0.87$; MMSE: $\left.r_{s}=-0.05, p=0.84\right)$. As expected, since CDR is highly dependent on activities of daily living, CDR sum of boxes correlated significantly with FAQ in all subjects $\left(r_{s}=0.66, p<0.0001\right)$ and in MCI subjects only $\left(r_{s}=0.55\right.$, $\mathrm{p}=0.0005)$.

The interval between clinical assessments and $\mathrm{PiB}$ PET scanning was $60.6 \pm 74.0$ days (mean \pm SD). For all subjects, global PiB DVR was $1.33 \pm 0.29$. For MCI subjects only, global PiB DVR was $1.37 \pm 0.32$, and for $\mathrm{NC}$ subjects only, global PiB DVR was $1.24 \pm 0.19(t=1.95$, $\mathrm{p}=0.057)$.

For our primary analysis in all subjects using the linear multiple regression model including age, AMNART IQ, MMSE, and RAVLT delayed recall, we found a significant partialed relationship between greater IADL impairment and greater global $\mathrm{PiB}$ retention $\left(\mathrm{R}^{2}=0.40, \mathrm{p}<\right.$ 0.0001 for model; unstandardized partial regression $\mathrm{Co}-$ efficient, $\beta=5.8, p=0.0002,95 \%$ CI for $\beta=2.9-8.7$ ) (fig. 2, 3). Using this model, we predict that for each 1-unit increase in global PiB DVR, a 5.8 increase in FAQ will result.

When looking at MCI subjects only, using the linear multiple regression model including age and AMNART IQ, we found a significant partialed relationship between greater IADL impairment and greater global $\mathrm{PiB}$ retention $\left(\mathrm{R}^{2}=0.28, \mathrm{p}=0.013\right.$ for model; $\beta=6.1, \mathrm{p}=0.003$, $95 \%$ CI for $\beta=2.2,10.0$ ) (fig. 2,4 ). Using this model, we predict that for each 1-unit increase in global PiB DVR, a 6.1-unit increase in FAQ will result. When including MMSE and RAVLT delayed recall in the model, the re- 


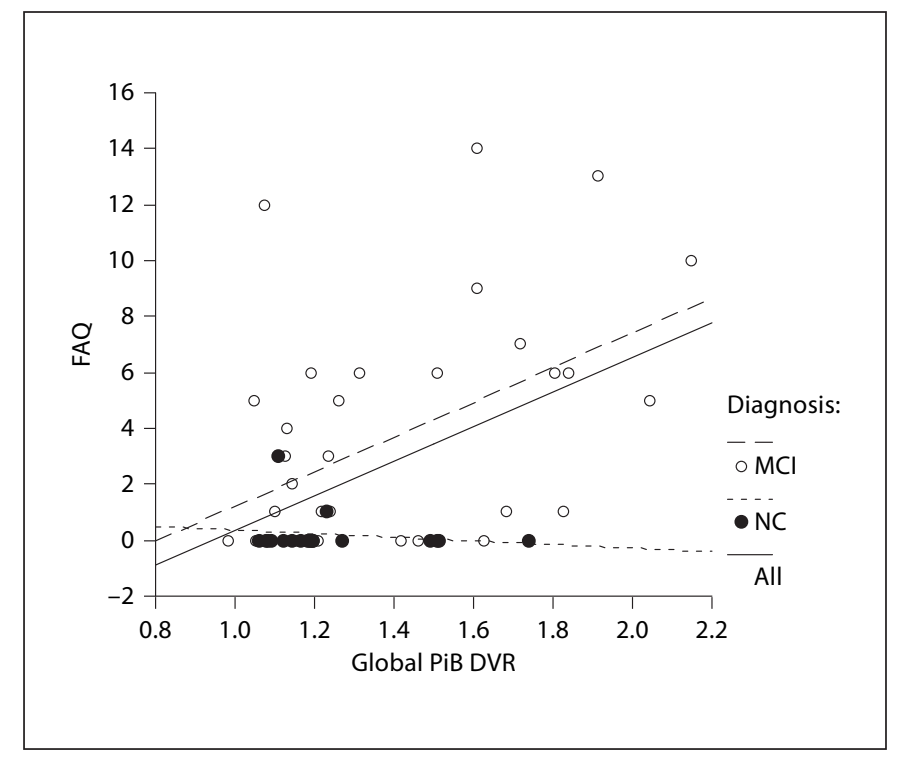

Fig. 2. Scatter plot of global PiB DVR vs. FAQ in NC, MCI, and all subjects. There is a significant positive partial Spearman's rank correlation between global $\mathrm{PiB}$ retention and FAQ (higher scores indicate greater IADL impairment) in all subjects $\left(\mathrm{pr}_{\mathrm{s}}=0.45, \mathrm{p}=\right.$ $0.001)$ and in MCI subjects only $\left(\mathrm{pr}_{\mathrm{s}}=0.50, \mathrm{p}=0.002\right)$, but not in NC subjects only $\left(\mathrm{pr}_{\mathrm{s}}=0.04, \mathrm{p}=0.89\right)$.

sults were unaltered $\left(R^{2}=0.37, p=0.014\right.$ for model; $\beta=$ $6.3, \mathrm{p}=0.002,95 \% \mathrm{CI}$ for $\beta=2.5-10.2$ ).

When looking at $\mathrm{NC}$ subjects only, using the linear multiple regression model including age and AMNART IQ, as expected, we did not find a significant partialed relationship between greater IADL impairment and greater global $\mathrm{PiB}$ retention $\left(\mathrm{R}^{2}=0.12, \mathrm{p}=0.59\right.$ for model; $\beta=-0.4, p=0.66,95 \% \mathrm{CI}$ for $\beta=-2.5$ to 1.7 ) (fig. 2 ).

The results of the linear multiple regression models were confirmed with partial Spearman's rank correlations in all subjects $\left(\mathrm{pr}_{\mathrm{s}}=0.45, \mathrm{p}=0.001\right)$, MCI subjects only $\left(\mathrm{pr}_{\mathrm{s}}=0.50, \mathrm{p}=0.002\right)$, and $\mathrm{NC}$ subjects only $\left(\mathrm{pr}_{\mathrm{s}}=\right.$ $0.04, \mathrm{p}=0.89)$. Significant partial correlations between greater IADL impairment and greater global $\mathrm{PiB}$ retention were seen in all subjects and in MCI subjects only, but not in NC subjects only.

In the exploratory regional analysis in all subjects, we found a significant association between greater IADL impairment and greater regional $\mathrm{PiB}$ retention in 5 of the 6 regions with $\mathrm{r}_{\mathrm{s}}$ ranging from 0.28 to $0.46(\mathrm{p}<0.05)$. There was no significant association with medial temporal $\mathrm{PiB}$ retention. As expected, all regions were highly inter-correlated with $r_{s}$ ranging from 0.67 to 0.90 . Since $\mathrm{PiB}$ retention regions were highly inter-correlated, it ap-

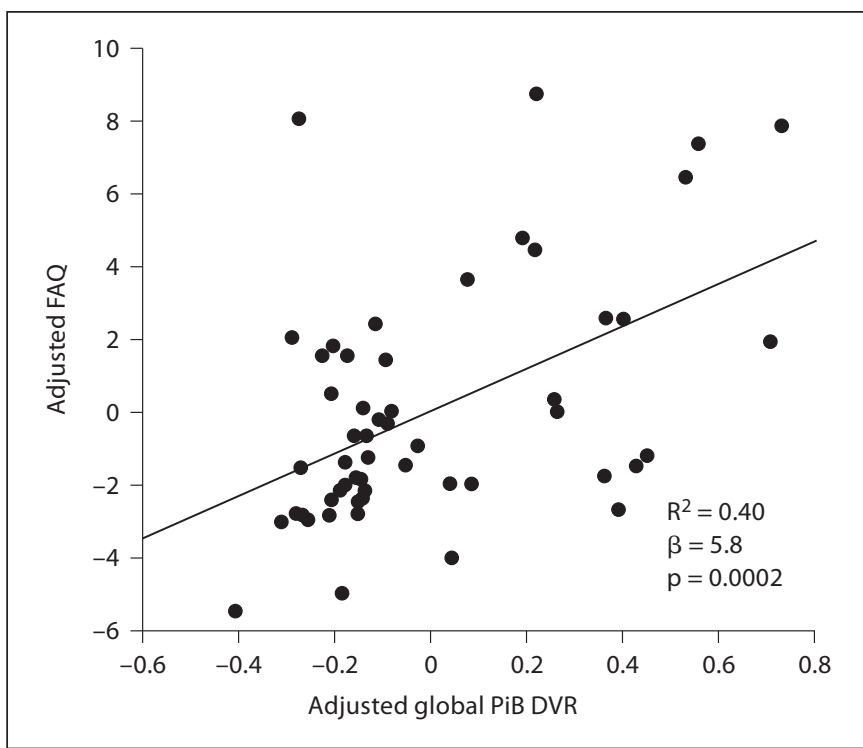

Fig. 3. Partial regression plot of adjusted global PiB DVR versus adjusted FAQ in all subjects. Global PiB DVR and FAQ have been adjusted for all other predictors in the model, including age, AMNART IQ, MMSE, and RAVLT delayed recall.

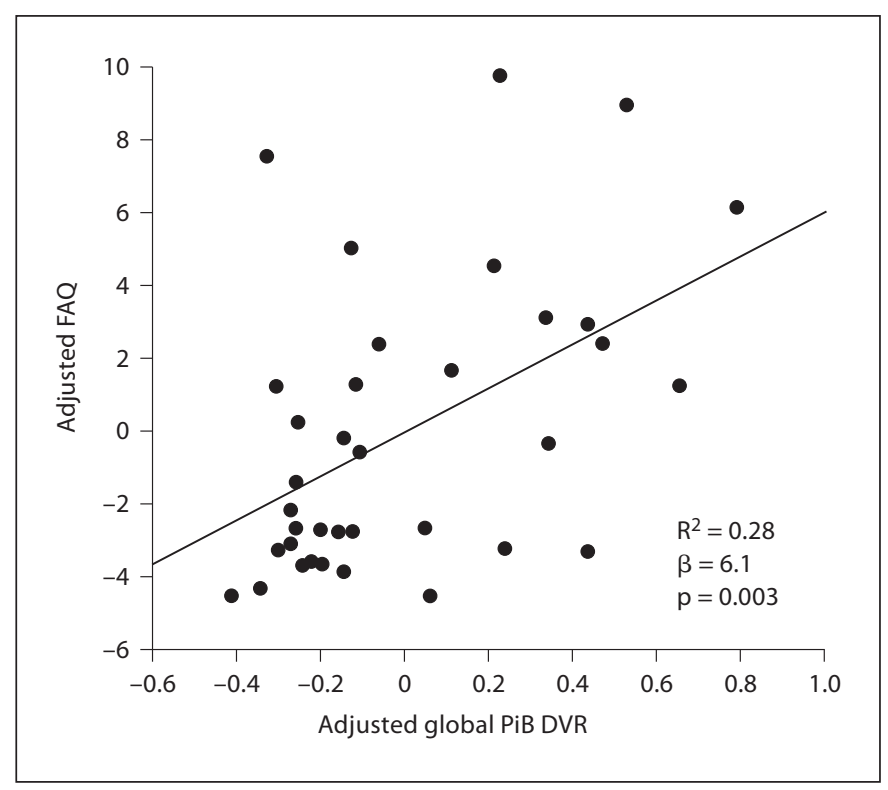

Fig. 4. Partial regression plot of adjusted global PiB DVR versus adjusted FAQ in MCI subjects only. Global PiB DVR and FAQ have been adjusted for all other predictors in the model, including age and AMNART IQ. 
peared that the clinical association with $\mathrm{PiB}$ retention was global. When looking at MCI subjects only, similar results were obtained with significant associations between IADL impairment and regional $\mathrm{PiB}$ retention. When looking at NC subjects only, there were no significant associations between IADL impairment and regional $\mathrm{PiB}$ retention.

\section{Discussion}

These results suggest that daily functional impairment is associated with greater amyloid burden within a sample of MCI and NC subjects, independent of age, cognitive reserve, global cognitive impairment, and memory performance. Specifically, global $\mathrm{PiB}$ retention was associated with IADL impairment in this mildly impaired group of subjects. This finding is in agreement with another study where the CDR, in which 3 of 6 items rate activities of daily living, was associated with $\mathrm{PiB}$ retention across a sample of $\mathrm{NC}, \mathrm{MCI}$, and various dementia subjects [7], as well as another study where CDR sum of boxes was related to $\mathrm{PiB}$ retention in a sample that included NC and AD subjects [15]. These two studies did not control for global cognitive impairment or memory impairment, as was done in the current study for the entire sample. Therefore, the association between global $\mathrm{PiB}$ retention and IADL impairment in the current study is not a potentially spurious one due to an IADL-global cognition or IADL-memory connection. Similarly, a postmortem study demonstrated a relationship between global amyloid pathology and activities of daily living impairment in severe AD [2]. The current study extends the findings of the studies cited above to subjects with much milder cognitive deficits as evidenced by a mean CDR sum of boxes of 1.5 in the MCI subgroup.

As anticipated, the relationship of IADL impairment to amyloid deposition did not hold among NC subjects in the current analyses, given the apparent lack of IADL impairment in this group. Thus, the results of the current analyses appear to be driven by the MCI subgroup. However, this observation should be interpreted in the context of published findings [15] in the normal elderly relating amyloid deposition to memory performance, particularly in difficult list-learning tasks. It is possible that the measure of IADL used in the current study (FAQ) is insufficiently sensitive to milder forms of functional difficulty and that a more sensitive measure would be more revealing in cognitively normal subjects. The develop- ment of such a sensitive measure of IADL will be an important future direction. On the other hand, even in very mildly impaired MCI subjects, it appears that the FAQ is a sensitive measure that can be related to important $\mathrm{AD}$ biomarkers such as $\mathrm{PiB}$ retention.

We also explored the relationship between regional $\mathrm{PiB}$ retention and IADL impairment. A prior study employing ${ }^{18} \mathrm{~F}$-fluorodeoxyglucose PET showed that IADL impairment was associated with posterior hypometabolism in $\mathrm{AD}$ [1]. The default network, which is linked to memory function, has important foci in the medial parietal cortices, which have recently been linked further to increased $\mathrm{PiB}$ retention in $\mathrm{MCI}$ and $\mathrm{AD}[8,17]$. We therefore suspected that increased $\mathrm{PiB}$ retention in default network regions might be associated with IADL impairment. However, the current analysis revealed that all cortical PiB regions explored were highly inter-correlated and similarly associated with IADL impairment (except for medial temporal). Thus, it appears that the association is with global $\mathrm{PiB}$ retention rather than any region in particular, as previously seen in other PiB-clinical association studies [18].

$\mathrm{PiB}$ studies and postmortem studies of MCI have demonstrated variable pathology and have shown that only about half of MCI subjects have increased amyloid burden $[8-10,12]$. The current study showed that mild impairment in IADL even in the early stages of MCI is associated with increased amyloid burden, thus further increasing the likelihood of the underlying pathology in this subset of MCI subjects being consistent with AD. If future longitudinal studies demonstrate that increased amyloid burden in very mildly impaired MCI subjects predicts future functional decline and progression to dementia, such a subset of mildly impaired subjects with likely AD pathology would be suitable for a clinical trial of a disease-modifying agent with both PET and IADL measures (or a global measure such as CDR sum of boxes) as endpoints.

The current study has several limitations. Subjects participating in ADNI and the investigator-initiated ADNI ancillary study were selected carefully to meet NC and amnestic MCI criteria; subjects with significant medical issues, psychiatric disorders, or neurological conditions were excluded. Therefore, this particular sample may not generalize well to the rest of the population. However, the amnestic MCI subjects in this study represent subjects who are more likely to have AD pathology and therefore are optimally suited for analyses exploring $\mathrm{PiB}$ retention. Another issue in these analyses was the high level of education (16.6 \pm 2.8 years) and premorbid 
intelligence (AMNART IQ $120.8 \pm 10.4$ ) of the participating subjects, suggesting they might have a high level of cognitive reserve. This reflects the subjects who commonly volunteer for such studies at tertiary referral centers which have the resources to perform PiB PET scans. Consequently, premorbid intelligence, which was highly correlated with education, was accounted for in the analyses performed here. Finally, our outcome measure of IADL (FAQ) had a non-normal distribution (skewed to the right), which could have led to a violation of the linear assumption in the multiple regression models employed in our analyses. However, the results were confirmed using a non-parametric test, partial Spearman's rank correlation. Therefore, we are confident that the association between greater $\mathrm{PiB}$ retention and greater IADL impairment across all subjects and in the MCI subset is valid.

In conclusion, global cortical amyloid burden was associated with IADL impairment in MCI in the current study. Future longitudinal studies will help determine whether early amyloid deposition will predict rapid functional decline and progression to dementia.

\section{Acknowledgements}

This study was supported by R01 AG027435S, 1K23AG033634, the Rosalinde and Arthur Gilbert Foundation/AFAR New Investigator Awards in Alzheimer's Disease, the Massachusetts Alzheimer's Disease Research Center (P50 AG005134), and the ADNI National Institutes of Health grant U01 AG024904). ADNI is funded by the National Institute on Aging, the National Institute of Biomedical Imaging and Bioengineering, and through generous contributions from the following: Abbott, AstraZeneca AB, Bayer Schering Pharma AG, Bristol-Myers Squibb, Eisai Global Clinical Development, Elan Corporation, Genentech, GE Healthcare, GlaxoSmithKline, Innogenetics, Johnson and Johnson, Eli Lilly and Co., Medpace, Inc., Merck and Co., Inc., Novartis AG, Pfizer Inc., F. Hoffman-La Roche, Schering-Plough, Synarc, Inc., as well as non-profit partners the Alzheimer's Association and Alzheimer's Drug Discovery Foundation, with participation from the US Food and Drug Administration. Private sector contributions to ADNI are facilitated by the Foundation for the National Institutes of Health (www.fnih.org). The grantee organization is the Northern California Institute for Research and Education, and the study is coordinated by the Alzheimer's Disease Cooperative Study at the University of California, San Diego. ADNI data are disseminated by the Laboratory for Neuro Imaging at the University of California, Los Angeles. This research was also supported by National Institutes of Health grants P30 AG010129 and K01 AG030514, and the Dana Foundation.

\section{References}

1 Salmon E, Lespagnard S, Marique P, Peeters F, Herholz K, Perani D, Holthoff V, Kalbe E, Anchisi D, Adam S, Collette F, Garraux G: Cerebral metabolic correlates of four dementia scales in Alzheimer's disease. J Neurol 2005;252:283-290.

-2 Marshall GA, Fairbanks LA, Tekin S, Vinters HV, Cummings JL: Neuropathologic correlates of activities of daily living in Alzheimer disease. Alzheimer Dis Assoc Disord 2006; 20:56-59.

-3 Klunk WE, Engler H, Nordberg A, Wang Y, Blomqvist G, Holt DP, Bergstrom M, Savitcheva I, Huang GF, Estrada S, Ausen B, Debnath ML, Barletta J, Price JC, Sandell J, Lopresti BJ, Wall A, Koivisto P, Antoni G, Mathis CA, Langstrom B: Imaging brain amyloid in Alzheimer's disease with Pittsburgh Compound-B. Ann Neurol 2004;55:306-319.

-4 Forsberg A, Engler H, Almkvist O, Blomquist G, Hagman G, Wall A, Ringheim A, Långström B, Nordberg A: PET imaging of amyloid deposition in patients with mild cognitive impairment. Neurobiol Aging 2008;29: 1456-1465.

$\checkmark 5$ Kemppainen NM, Aalto S, Wilson IA, Nagren K, Helin S, Bruck A, Oikonen V, Kailajarvi M, Scheinin M, Viitanen M, Parkkola R, Rinne JO: PET amyloid ligand [11C]PIB uptake is increased in mild cognitive impairment. Neurology 2007;68:1603-1606.
-6 Lopresti BJ, Klunk WE, Mathis CA, Hoge JA, Ziolko SK, Lu X, Meltzer CC, Schimmel K, Tsopelas ND, Dekosky ST, Price JC: Simplified quantification of Pittsburgh Compound $B$ amyloid imaging PET studies: a comparative analysis. J Nucl Med 2005;46:1959-1972.

-7 Rowe CC, Ng S, Ackermann U, Gong SJ, Pike K, Savage G, Cowie TF, Dickinson KL, Maruff P, Darby D, Smith C, Woodward M, Merory J, Tochon-Danguy H, O'Keefe G, Klunk WE, Mathis CA, Price JC, Masters CL, Villemagne VL: Imaging beta-amyloid burden in aging and dementia. Neurology 2007;68:1718-1725.

-8 Sperling RA, Laviolette PS, O’Keefe K, O'Brien J, Rentz DM, Pihlajamaki M, Marshall G, Hyman BT, Selkoe DJ, Hedden T, Buckner RL, Becker JA, Johnson KA: Amyloid deposition is associated with impaired default network function in older persons without dementia. Neuron 2009;63:178-188.

-9 Wolk DA, Price JC, Saxton JA, Snitz BE, James JA, Lopez OL, Aizenstein HJ, Cohen AD, Weissfeld LA, Mathis CA, Klunk WE, De-Kosky ST: Amyloid imaging in mild cognitive impairment subtypes. Ann Neurol 2009;65:557-568.
10 Jack CR Jr, Lowe VJ, Senjem ML, Weigand SD, Kemp BJ, Shiung MM, Knopman DS, Boeve BF, Klunk WE, Mathis CA, Petersen $\mathrm{RC}:{ }^{11} \mathrm{C} \mathrm{PiB}$ and structural MRI provide complementary information in imaging of Alzheimer's disease and amnestic mild cognitive impairment. Brain 2008;131:665-680.

11 Bennett DA, Schneider JA, Bienias JL, Evans DA, Wilson RS: Mild cognitive impairment is related to Alzheimer disease pathology and cerebral infarctions. Neurology 2005;64: 834-841.

12 Petersen RC, Parisi JE, Dickson DW, Johnson KA, Knopman DS, Boeve BF, Jicha GA, Ivnik RJ, Smith GE, Tangalos EG, Braak H, Kokmen E: Neuropathologic features of amnestic mild cognitive impairment. Arch Neurol 2006;63:665-672.

13 Edison P, Archer HA, Hinz R, Hammers A, Pavese N, Tai YF, Hotton G, Cutler D, Fox N, Kennedy A, Rossor M, Brooks DJ: Amyloid, hypometabolism, and cognition in Alzheimer disease: an [11C]PIB and [18F]FDG PET study. Neurology 2007;68:501-508.

14 Engler H, Forsberg A, Almkvist O, Blomquist G, Larsson E, Savitcheva I, Wall A, Ringheim A, Langstrom B, Nordberg A: Two-year follow-up of amyloid deposition in patients with Alzheimer's disease. Brain 2006;129: 2856-2866. 
-15 Rentz DM, Locascio JJ, Becker JA, Moran EK, Eng E, Buckner RL, Sperling RA, Johnson KA: Cognition, reserve, and amyloid deposition in normal aging. Ann Neurol 2010; 67:353-364.

16 Morris JC: The Clinical Dementia Rating (CDR): current version and scoring rules. Neurology 1993;43:2412-2414.

-17 Buckner RL, Sepulcre J, Talukdar T, Krienen FM, Liu H, Hedden T, Andrews-Hanna JR, Sperling RA, Johnson KA: Cortical hubs revealed by intrinsic functional connectivity: mapping, assessment of stability, and relation to Alzheimer's disease. J Neurosci 2009; 29:1860-1873.

18 Becker JA, Hedden T, Carmasin J, Maye J, Rentz DM, Putcha D, Fischl B, Greve D, Marshall GA, Salloway S, Marks D, Buckner RL, Sperling RA, Johnson KA: Amyloid- $\beta$ associated cortical thinning in clinically normal elderly. Ann Neurol 2010, E-pub ahead of print.

-19 Gomperts SN, Rentz DM, Moran E, Becker JA, Locascio JJ, Klunk WE, Mathis CA, Elmaleh DR, Shoup T, Fischman AJ, Hyman BT, Growdon JH, Johnson KA: Imaging amyloid deposition in Lewy body diseases. Neurology 2008;71:903-910.

$\checkmark 20$ Rabinovici GD, Furst AJ, Alkalay A, Racine CA, O’Neil JP, Janabi M, Baker SL, Agarwal N, Bonasera SJ, Mormino EC, Weiner MW, Gorno-Tempini ML, Rosen HJ, Miller BL, Jagust WJ: Increased metabolic vulnerability in early-onset Alzheimer's disease is not related to amyloid burden. Brain 2010;133: 512-528.

-21 Mueller SG, Weiner MW, Thal LJ, Petersen RC, Jack C, Jagust W, Trojanowski JQ, Toga AW, Beckett L: The Alzheimer's Disease Neuroimaging Initiative. Neuroimaging Clin N Am 2005; 15:869-877.
22 Sheikh JI, Yesavage JA: Geriatric Depression Scale (GDS): recent evidence and development of a shorter version; in Brink $\mathrm{T}$ (ed): Clinical Gerontology: A Guide to Assessment and Intervention. New York, Haworth Press, 1986, pp 165-173.

23 Yesavage JA, Brink TL, Rose TL, Lum O, Huang V, Adey M, Leirer VO: Development and validation of a geriatric depression screening scale: a preliminary report. J Psychiatr Res 1982;17:37-49.

24 Rosen WG, Terry RD, Fuld PA, Katzman R, Peck A: Pathological verification of ischemic score in differentiation of dementias. Ann Neurol 1980;7:486-488.

25 Folstein MF, Folstein SE, McHugh PR: 'Mini-Mental State': a practical method for grading the cognitive state of patients for the clinician. J Psychiatr Res 1975;12:189-198.

26 Petersen RC: Mild cognitive impairment as a diagnostic entity. J Intern Med 2004;256: 183-194.

27 Weschler D: Weschler Memory Scale Revised Manual (WMS-R). New York, Psychological Corporation, 1987.

28 Pfeffer RI, Kurosaki TT, Harrah CH Jr, Chance JM, Filos S: Measurement of functional activities in older adults in the community. J Gerontol 1982;37:323-329.

29 Nitrini R, Caramelli P, Herrera E Jr, Bahia VS, Caixeta LF, Radanovic M, Anghinah R, Charchat-Fichman $\mathrm{H}$, Porto CS, Carthery MT, Hartmann AP, Huang N, Smid J, Lima EP, Takada LT, Takahashi DY: Incidence of dementia in a community-dwelling Brazilian population. Alzheimer Dis Assoc Disord 2004;18:241-246.

30 Rey A: L'examen clinique en psychologie. Paris, Presses Universitaires de France, 1964.
31 Nelson HE, O’Connell A: Dementia: the estimation of premorbid intelligence levels using the New Adult Reading Test. Cortex 1978;14:234-244.

32 Mathis CA, Wang Y, Holt DP, Huang GF, Debnath ML, Klunk WE: Synthesis and evaluation of ${ }^{11} \mathrm{C}$-labeled 6-substituted 2-arylbenzothiazoles as amyloid imaging agents. J Med Chem 2003;46:2740-2754.

-33 Johnson KA, Gregas M, Becker JA, Kinnecom C, Salat DH, Moran EK, Smith EE, Rosand J, Rentz DM, Klunk WE, Mathis CA, Price JC, DeKosky ST, Fischman AJ, Greenberg SM: Imaging of amyloid burden and distribution in cerebral amyloid angiopathy. Ann Neurol 2007;62:229-234.

34 Price JC, Klunk WE, Lopresti BJ, Lu X, Hoge JA, Ziolko SK, Holt DP, Meltzer CC, DeKosky ST, Mathis CA: Kinetic modeling of amyloid binding in humans using PET imaging and Pittsburgh Compound-B. J Cereb Blood Flow Metab 2005;25:1528-1547.

35 Tzourio-Mazoyer N, Landeau B, Papathanassiou D, Crivello F, Etard O, Delcroix N, Mazoyer B, Joliot M: Automated anatomical labeling of activations in SPM using a macroscopic anatomical parcellation of the MNI MRI single-subject brain. Neuroimage 2002; 15:273-289.

\36 Hedden T, Van Dijk KR, Becker JA, Mehta A, Sperling RA, Johnson KA, Buckner RL: Disruption of functional connectivity in clinically normal older adults harboring amyloid burden. J Neurosci 2009;29:12686-12694.

37 Mintun MA, Larossa GN, Sheline YI, Dence CS, Lee SY, Mach RH, Klunk WE, Mathis CA, DeKosky ST, Morris JC: [11C]PIB in a nondemented population: potential antecedent marker of Alzheimer disease. Neurology 2006;67:446-452. 